\section{One of the places to get together}

\section{O.H. Petersen}

Clinical Physiology and Biochemistry.

Editors-in-chief J. Rosenthal and M.

Rafelson.

Karger. 6/yr. DM 290, \$110.

AFTER a long time of ever-increasing specialization, resulting in smaller and smaller branches on the physiology tree, we now seem to have entered a period of reunification. One of the stated aims of Clinical Physiology and Biochemistry (CPB), "designed to provide a vehicle for scientific communications amongst clinicians, physiologists and biochemists", is "to re-emphasize those areas of common biologic interest that already exist"'. To some extent therefore it will be in competition with the older physiological journals, established before the fragmentation of the subject became a

\section{Clinical Physiology and Biochemistry}

problem, of which at least Pflügers Archiv and the Quarterly Journal of Experimental Physiology deliberately take a broad view of physiology and include pathophysiological papers as long as they serve the purposes of the subject as a basic science.

Many of the papers so far published in CPB could, at least as far as the subject matter is concerned, have appeared in any of a number of physiological or biochemical journals. These papers are of a reasonable standard without being overexciting - as usual with a new journal only time will tell if it will be possible to attract really high-quality papers away from the broad-based journals covering the whole range of the physiological sciences, or from the journals covering the interface between the basic sciences and clinical investigations (such as the very successful Journal of Clinical Investigation), as well as from the many good multidisciplinary "systems" journals.

The editorial board appears to be somewhat narrowly based as an almost exclusive American-German enterprise, but CPB is the official journal of the National Academy of Clinical Biochemistry and presumably has a reasonably secure financial position. Only original papers are considered and there appears to be no wish to publish letters or notes. The delay from manuscript submission to publication seems long, particularly for a new journal; thus most of the papers in the July-August 1984 issue were received in August-September 1983. The quality of the production is good with

biomedical research and toxicity testing.

Will the new journal find a niche? It

figures of uniform standard and the text se out in the now-usual two-column format.

The journal faces tough competition from a number of very different but well entrenched rivals. It will undoubtedly, as stated in the first editorial, serve as $a$ forum to foster interdisciplinary exchange of information and concepts, but I am not so sure that it will become the major platform for this important exercise.

O.H. Petersen is George Holt Professor of Physiology at the University of Liverpool.

\section{Infant alternatives}

\section{W.D.M. Paton}

ATLA (Alternatives to Laboratory

Animals).

Editors Michael Balls, Rosemary Riddell and Alastair Worden.

FRAME, $5 b$ The Poultry, Bank Place, Nottingham NG1 2JR, UK. 4/yr. £16.

ALTHOUGH labelled Volume 11, the issues of ATLA on which this review is based are indeed the manifestation of a new journal. The original venture, ATLA Abstracts, born in 1973, was not a success, probably because it was competing with more professional abstracting services, and perhaps also because it underestimated the extent to which biomedical scientists were already using non-animal methods. But the new journal, backed by an excellent editorial board, is a different proposition. Its policy (outlined in the first issue) remains that of its parent body, the Fund for the Replacement of Animals in Medical Experiments; but instead of abstracts, it includes research papers, general articles, correspondence, news, book reviews, and a list of titles covering all aspects of alternatives to laboratory animals in

\section{Science at play}

\section{E.C. Frederick}

Journal of Sports Sciences.

Editor Thomas Reilly.

E. \& F.N. Spon. 3/yr. £39.50, \$84.50.

Sports Medicine.

Editor-in-chief Rennie C. Heel.

ADIS Press, PO Box 34-030, Birkenhead,

Auckland 10, New Zealand. 6/yr. \$95, SwFr. 210.

PUBLISHERS have responded slowly to the furious growth in sports science over the past decade. At a time when the number of researchers was doubling and tripling, the number of journal pages expanded in slow motion. As a consequence, long publication delays and abnormally high rejection rates became the norm.

Although some of the pressure was deserves a chance. The news items are really valuable; nowhere else does one find, for instance, rational analysis of animal experiments from around the world, or compact accounts of the innumerable meetings now taking place. The research papers are mixed: some would hardly be published elsewhere, some are worthwhile. Although they would overlap with other journals, why not have a special place where (say) toxicity tests deliberately shaped to reduce animal use can readily be found? It is up to the editors to ensure the merit of such contributions, the only ultimate guarantee of their being read. The correspondence and book reviews could be equally useful. By contrast the melancholy, unorganized caravanserai of selected titles at the end of each issue seems useless; but again, if classified by technique, substance tested or general topic, with an author index, such a list could also be helpful.

The main difficulty for the journal however, may be strategic. One gets the sense of a battle being fought on two fronts: on the one hand a liking for verbal fisticuffs with the biomedical "establishment", of a type perhaps needful to retain support from the more anti-experiment clientele of FRAME; on the other a genuine scientific and critical approach to research, of the type winning respect from the investigator. Fisticuffs are quite fun, and rather encouraged these days, but are boring to re-read and do not wear well (except in the hands of a Housman, Leavis or Medawar). Dr Balls and his colleagues have a tricky task in child-rearing: one hopes that it is an occasional gentle irony (a tutorial with Lewis Thomas would do) along with some meat that finally clothes this promising infant.

Sir William Paton retires this month as Professor of Pharmacology, University of Oxford.

relieved by the introduction in 1980 of the International Journal of Sports Medicine, and by modest increases in issue size and frequency by many existing journals, it was not until the recent spate of new journals that sports science researchers finally found some breathing room. Two contenders for our papers and our subscriptions that should be mentioned in passing are the International Journal of Sports Biomechanics (which has just released its first issue and so it is too soon to gauge its scholarly impact), and Human Movement Science. The latter espouses an editorial policy encompassing most of the constituent disciplines of sports science, but up to this point has largely published motor-learning papers of somewhat specialist appeal.

The two newcomers that deserve more detailed description, and are reviewed here, are the Journal of Sports Sciences (JSS) and Sports Medicine (SM). The 